In the first half, point groups, Bravais lattices, space groups, stereographic projections and the like are discussed in a superficial but broad way which would not satisfy nor help any serious student. It is sad that here the sixth-former is given no idea of the existence of the most interesting of point groups - the icosahedral groupsimply because a lattice with five-fold symmetry cannot occur and is therefore not covered in formal university courses.

The next quarter concerns crystalline forces, well covered in standard texts which any school can afford if it can afford this expensive book. The argument in favour of this book must be that it covers the ground of many others. In fact, the first three-quarters are covered so well by a few well-accepted texts that all justification rests on the last quarter. Here we have band theory of semiconductors, colour centres, dislocations, fibres, liquids, coloured symmetry, group theory, cut-out model building, and erystal growing, squashed together, but on most of these topics the coverage is quick and shallow.

This book should really be reviewed by a sixth-former with time and motivation for background reading, but I trust I have been successful in reliving these days.

G. S. Pawley

\section{HISTORICAL CRYSTALLOGRAPHY}

\section{Early Papers on Diffraction of X-rays by Crystals}

Edited by J. M. Bijvoet, W. G. Burgers and G. Hägg. Pp. xvi+372. (Oosthoek's Uitgebersmaatschappij NV: Utrecht, 1969. Published for the International Union of Crystallography.) 114s.

Crystallographers are well organized people. They have an active international union, and there is even a World Directory of Crystallographers. Very rightly, they are now taking a serious interest in the history of their subject. This volume follows Fifty Years of $X$-ray Diffraction, which was edited by P. P. Ewald and appeared in 1962. It contains, in full or in part, more than eighty papers in the original language of publication, English, French or German. In a few eases, the condensation has been rather severe, so that scarcely more than the introductory and final paragraphs are reproduced. According to the foreword, the book (which will be followed by a second part) is intended "not only to serve as a pedagogic aid, but also to make the student aware of the history of science". Personally, I feel that a collection of original papers in any subject, except during the short period before good textbooks can be written, is a poor substitute for the latter. Its direct pedagogic value may be slight, but the book will be of enormous interest to teachers and researchers in crystallography. WILLIAM CochraN

\section{CRYSTAL CHEMISTRY}

\section{Inorganic Crystal Chemistry}

By István Náray-Szabó. Pp. 480. (Akadémiai Kiadó: Budapest, 1969.) 168s.

The link that was first forged more than fifty years ago between crystal structure analysis and investigations of the nature of the chemical bond has, if anything, become more important during the past decade. There has been an enormous increase in the productivity of chemical crystallographers as a result of the advent of electronic computers and automation of data collection and processing. For my part, these developments have not carried with them the fashionable cry of "more means worse"-indeed, the reverse is true, for one now has to hand structural results on a large number of closely related molecules or complex ions which put severe demands on any theory which has pretensions to being of general value. Even so, the sheer volumo of results increases tho nocd for really good review's of the results which are not mere catalogues; the profound influence of, say, Pauling's first edition of The Nature of the Chemical Bond cannot be forgotten.

Náray-Szabó puts himself at a severe disadvantage, for his discussions of the chemical bond are kept to a very primitive level. The blurb suggests that here is something new-." the system of elements and inorganic compounds, discussed strictly following the periodic table, givos a survey of inorganic chemistry on this basis for the first time". Even so, the book does contain references to structural work which was completed as late as 1968 so that it has somo obvious, if ephemeral, advantages over its predecessors. 'Two sections, of very unequal length, deal with geometrical crystallography and systematic crystal chemistry. The first is written in a straightforward and conventional way, but some very misleading statements are made early in the crystal chemistry section on the nature of the bonds in ionic crystals, diamond and metals as "evidenced" from Fourier syntheses of electron density; there is, for example, no discussion of the more recent and definitive work on the bonding electron density distribution in diamond and other crystals. The descriptive part of the erystal chemistry section is quite well done and the illustrations are first class, but I do not believe that these will be sufficient to make the individual research worker pay a high price for material which is, in general, no more critical than computer-retrieved results. R. MAsov

\section{FLUORINE CHEMISTRY}

\section{The Chemistry of Fluorine and its Compounds}

By H. J. Emeléus. (Current Chemical Concepts: A Series of Monographs. A Polytechnic Press of the Polytechnic Institute of Brooklyn Book.) Pp. ix +133 . (Academic Press : London and New York, May 1969.) $65 s$.

THIs monograph consists of a series of lectures presented at the Polytechnic Institute of Brooklyn to which has been added a bibliography providing references chiefly to reviews of the various fields. Some of the reactions described do not have their own references but, with some effort, the latter can be found in the reviews; no more could be expected in a book of this size.

The author points out that, up to now, the main emphasis in the field as a whole has been on preparative chemistry and he has set out to indicate, now that adequate preparative methods and techniques are available, what more needs to be done, and the ways in which the com. pounds which he has played such a large part in making can be used, for the further development of the subject. In this he is most successful, particularly in those chapters dealing with the halogen fluorides, the oxygen fluorides and the perfluoro-organometallic compounds. Other chapters deal with hypofluorites; fluorides of Group III; the carbon fluorides; fluorides of $\mathrm{Si}, \mathrm{Ge}, \mathrm{Sn}$ and $\mathrm{Pb}$; fluorides of $\mathrm{N}$ and related compounds; fluorides of $\mathrm{P}, \mathrm{As}$, $\mathrm{Sb}$ and $\mathrm{Bi}$; and fluorides of $\mathrm{S}, \mathrm{Se}$ and $\mathrm{Te}$. Some are very short and that on the carbon fluorides barely scratches the surface, but all provide sufficient stimulus to send the reader to the bibliography. The author's enthusiasm for the subject is apparent and cannot fail to be conveyed to his readers. As it stands, this book with its bibliography provides an excellent introduction to inorganic fluorine chemistry for undergraduates and research workers. Perhaps the author can eventually be prevailed on to expand it so as to deal with all the topics in greater detail and to include material, such as the noble gas derivatives, for which he is only able to quote references in the space available.

The title is too all-embracing; the content is largely inorganic. W. K. R. Musgrave 